\title{
The impact of indicated prevention and early intervention on co-morbid eating disorder and depressive symptoms: a systematic review
}

\author{
Rachel F Rodgers ${ }^{1,2,3}$ and Susan J Paxton ${ }^{3^{*}}$
}

\begin{abstract}
Background: Depressive and eating disorder symptoms are highly comorbid. To date, however, little is known regarding the efficacy of existing programs in decreasing concurrent eating disorder and depressive symptoms.

Methods: We conducted a systematic review of selective and indicated controlled prevention and early intervention programs that assessed both eating disorder and depressive symptoms.

Results: We identified a total of 26 studies. The large majority of identified interventions (92\%) were successful in decreasing eating disorder symptoms. However fewer than half (42\%) were successful in decreasing both eating disorder and depressive symptoms. Intervention and participant characteristics did not predict success in decreasing depressive symptoms.
\end{abstract}

Conclusions: Indicated prevention and early intervention programs targeting eating disorder symptoms are limited in their success in decreasing concurrent depressive symptoms. Further efforts to develop more efficient interventions that are successful in decreasing both eating disorder and depressive symptoms are warranted.

Keywords: Eating disorders, Depression, Prevention, Early intervention, Systematic review

\section{Review}

Eating disorders and depressive disorders have revealed strong associations, and their relationships contribute to the complexity, burden, and treatment resistance of these disorders [1]. In view of these factors, understanding the effects of prevention and early intervention efforts on both eating disorder and depressive symptoms is an important concern, and would help inform intervention. However, to date, little attention has been paid to the success of interventions in decreasing both of these concerns. The aim of the present study was therefore to conduct a systematic review of indicated prevention and early intervention programs that assessed both eating disorder and depressive symptoms in order to clarify the efficacy of these programs in decreasing both types of symptomatology.

The lifetime comorbidity between eating disorders and major depressive disorders is high with estimates of $40 \%$

\footnotetext{
* Correspondence: susan.paxton@latrobe.edu.au

${ }^{3}$ La Trobe University, Melbourne, Australia

Full list of author information is available at the end of the article
}

for Anorexia Nervosa and 50\% for Bulimia Nervosa [2]. Importantly, in relation to eating disorders, comorbid depressive symptoms have been found to negatively affect the successfulness of early intervention efforts. Depressive symptoms have been found to predict attrition in self-help programs for binge eating disorder [3], and to predict drop-out from Internet interventions that have become more numerous in recent years [4]. Similarly, depressive symptoms have been found to predict poorer prognosis in self-help programs for eating disorders [3].

Several types of relationships have been hypothesized and described between eating disorder and depressive symptoms, namely that 1) eating disorder and depressive symptoms may develop simultaneously; 2) eating disorder symptoms may be a risk factor for depressive symptoms; 3 ) depressive symptoms may be a risk factor for eating disorder symptoms. While all of these models have received empirical support [5-7], compelling evidence from twin studies has revealed the importance of shared genetic factors in the development of comorbid eating disorder and depressive symptoms $[8,9]$. In view of this, some authors have argued 
that the evidence to date provides greatest support for a comorbidity model in which eating disorders and depression stem from both common and specific etiological factors [10].

A number of theoretical models have proposed frameworks that account for these shared and specific risk factors including biological, cognitive, emotional-regulation, and feminist models. Biological models emphasize the importance of shared genetically transmitted biological factors, as described above, and in particular the importance of dysregulation of serotonergic pathways that have an impact on both mood and eating behaviors [11]. Cognitive models highlight the role of common cognitive distortions that play a role in the development of both depressive and eating disorder symptoms through a heightened focus on negative information [12-14]. Emotion-regulation models have revealed how maladaptive strategies for regulating emotions may contribute to both depressive and eating disorders symptoms [15]. Finally, feminist models of the comorbidity between depressive and eating disorder symptoms have highlighted the gendered aspects of these concerns and viewed both as products of the restricted roles accessible to women in Western society and the objectifying male gaze [16-18].

Despite the high rates of comorbidity and the number of theoretical frameworks accounting for this co-occurrence, to date little is known regarding the common course of eating disorder and depressive symptoms within interventions for high-risk individuals or early intervention programs. Previous work exploring the effect of prevention interventions for eating disorders on negative affect (which includes depressive symptoms but also more serious forms of negative affect) revealed that programs targeting individuals at high risk of eating disorders were more successful in decreasing negative affect [19]. Furthermore, programs including participants over the age of 15 , in interactive formats, and including psychoeducational and cognitive dissonance content, produced the greatest decreases in negative affect [19]. While these findings are useful, they may not be transposable to depressive symptoms in interventions for symptomatic individuals as negative affect has not been found to affect prevention intervention attrition [20,21]. Increasing our understanding of intervention effects on comorbid eating disorder and depressive symptoms is crucial as it has important clinical implications. In addition, this knowledge would convey important information regarding treatment efficiency and costs. Finally, strong theoretical bases exist for hypothesizing common underlying mechanisms accounting for eating disorder and depressive symptoms. However, a finding that interventions targeting these mechanisms (e.g., cognitive and emotional factors) were not successful in decreasing both types of symptomatology would point to a disconnect between theory and practice, and suggest a need for the theoretical accounts of the eating disorder/depression comorbidity to be revisited.

The aim of the present study was, therefore, to conduct a systematic review of interventions for high risk (indicated prevention) and symptomatic individuals (early intervention) that included both eating disorder and depression outcomes. Furthermore, consistent with previous findings [19], we expected that interventions that targeted individuals with higher initial levels of eating disorders and depressive symptoms would be most successful in decreasing both of these concerns. In addition, we hypothesized that interventions including a greater number of sessions, among younger participants (which might represent a shorter duration of symptoms), with content targeting negative thoughts and feelings would be most successful. Finally, as cognitivebehavioural therapy is widely recognized as one of the first line recommended treatments for depressive symptoms particularly among young people [22], we hypothesized that interventions implementing CBT strategies would be most successful in decreasing depressive symptoms.

\section{Methods}

This review was conducted in accordance to the PRISMA guidelines for systematic reviews [23]. The flow of information through different phases of the systematic review is shown in Figure 1.

\section{Data sources}

The databases PsychInfo, ScienceDirect and Scopus were searched for studies and dissertations published between January 1984 and September 2013. Two searches were conducted in each database, first a title search, second a keyword search. The searches included combinations of words describing eating concerns (eating AND disorder or disordered or disorders or pathology or disturbance or disturbed), body image concerns (body image or dissatisfaction or shape or appearance), depressive symptoms (depression or depressive or negative affect) and controlled interventions (prevention or intervention or evaluation or program or self-help AND control or controlled). In addition, studies included in previous reviews of the efficacy of interventions aiming to reduce eating concerns as well as the reference sections of relevant articles were scanned for additional potentially eligible studies.

\section{Study selection}

The resulting list of studies was inspected by one author to identify those meeting the following criteria:

(1)Peer-reviewed published work.

(2)Controlled intervention design, compared to an active or minimally active condition such as treatment as usual, or psychoeducation (randomised or not). 


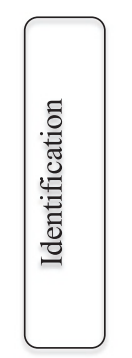

Records identified though database searching $(n=524)$
Additional records identified through other sources $(n=42)$

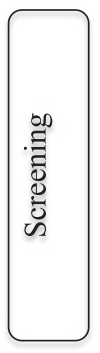

Records after duplicates removed $(n=446)$
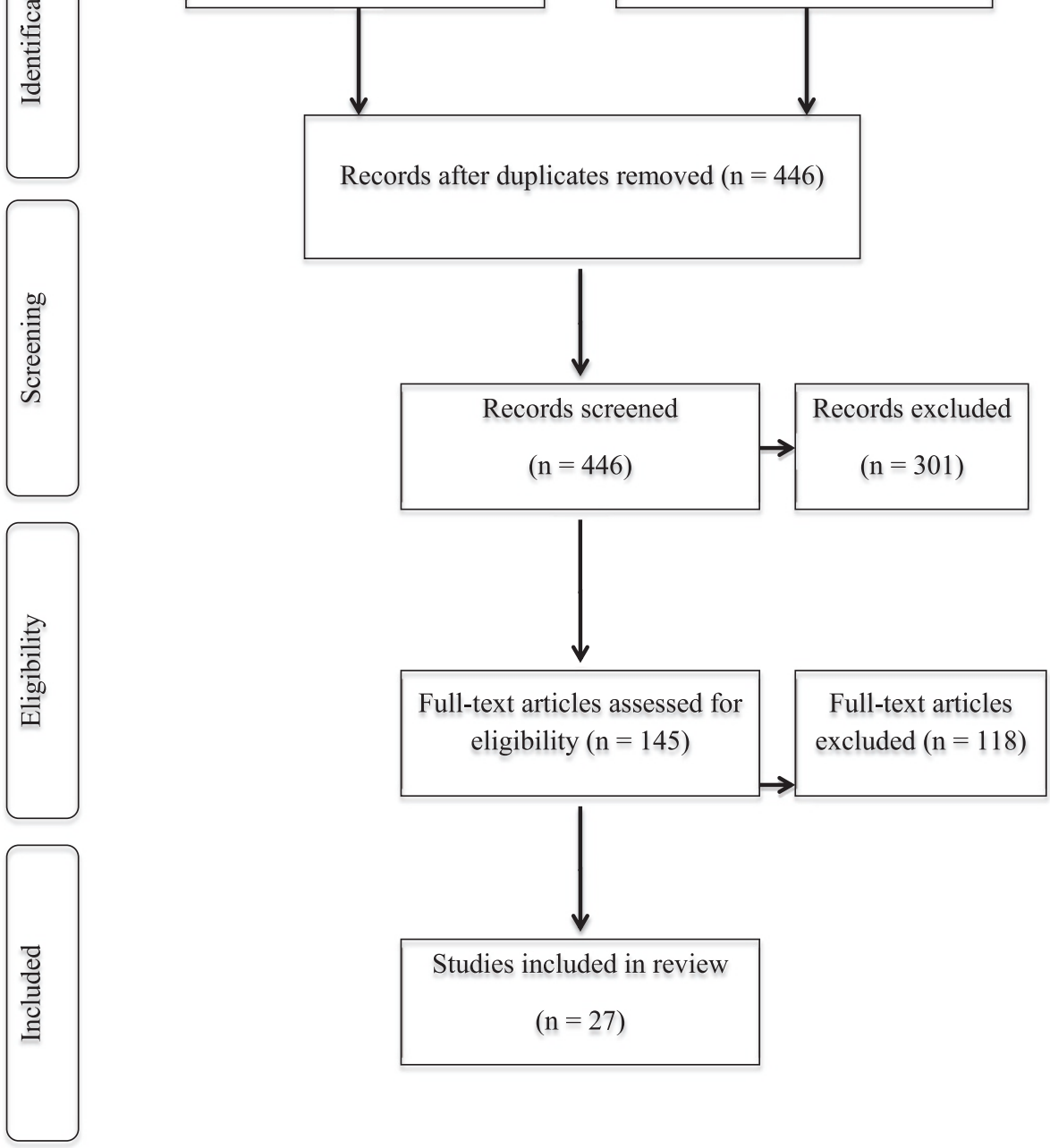

$(\mathrm{n}=27)$

Figure 1 Systematic literature review flow diagram. Flow of information through the different phases of the systematic review.

(3) Indicated interventions defined as interventions aimed at individuals who were identified as having minimal detectable signs or symptoms of an eating but did not meet diagnostic criteria [24]. In our review we included interventions that included participants who had been screened for symptoms as well as interventions allowing participants to self-select as having high levels of concern. In addition, we included self-help and guided self-help interventions as representing the lowest intensity treatment in a stepped care model [25].

(4) The concurrent assessment of both disordered eating and depressive symptoms at baseline and post-intervention, using psychometrically established measures for assessing both eating concerns and depressive symptoms.

\section{Data extraction}

Data from the reviewed studies were extracted by one author (RR). The data extraction sheet listed the following categories designed to describe and compare the studies mean age, gender, country, inclusion criteria for the study, type of intervention, mode of delivery, depression and eating disorder symptom measure, effects of intervention at post-test and follow-up, baseline depression level, number of intervention sessions, and presence of content targeting negative thoughts and emotions.

\section{Data analyses}

Depression scores were transformed into percentile ranks using norms from the general population [26,27]. Chi-square tests were conducted to explore the effect of 
initial ED levels operationalized by recruitment criteria (self-selected versus screened), CBT strategies, content targeting negative thoughts and feelings, and face-to-face delivery on successfully decreasing depressive symptoms, and successfully decreasing both depressive and eating disorder symptoms. Independent $\mathrm{t}$-tests were conducted to test the effect of mean age, number of sessions, and initial levels of depressive symptoms (percentile ranks) on successfully decreasing depressive symptoms, and successfully decreasing both depressive and eating disorder symptoms. All analyses were conducted using SPSS 22.

\section{Results}

Our review identified 26 studies corresponding to our inclusion criteria (Table 1). Of the 26,13 studies (50\%) were conducted in the U.S, 7 in Europe (27\%), 4 (15\%) in Australia, and 2 in Canada (8\%). The age of participants ranged from 14.4 to 46.5 years old. Nineteen of the studies (73\%) used the Beck Depression Inventory [28] as a measure of depressive symptoms, 3 (11\%) used the Center for Epidemiology Depression Scale [29], 1 (4\%) used the Montgomery-Asberg Depression Rating Scale, 1 (4\%) used the Schedule for Affective Disorders and Schizophrenia for School-Age Children [30], 1 (4.33\%) used the Kessler Distress Scale [31] and 1 (4\%) used the Hospital Anxiety and Depression Scale [32].

\section{Effect of interventions on eating disorder and depressive symptoms}

Of the 27 studies, 24 (92\%) revealed a statistically significant decrease in eating disorder symptoms while 12 (46\%) revealed a statistically significant decrease in depressive symptoms. Eleven studies (42\%) significantly decreased both depressive and eating disorder symptoms.

None of our hypothesized moderators of program success on depressive symptoms were supported. Programs with content targeting negative emotions or negative cognitions were not more likely to decrease depressive symptoms. Similarly, programs implementing CBT techniques were not more likely to decrease depressive symptoms. Furthermore, initial levels of depressive or eating disorder symptoms, age, and number of sessions also revealed no association with intervention efficacy in decreasing depressive symptoms (Table 2).

Similarly, none of the hypothesized moderators were able to distinguish between programs that successfully decreased both depressive and eating disorder symptoms, and those that were successful in decreasing only one, or none (Table 2). However, there was a trend for number of sessions, $\mathrm{t}(24)=1.75, \mathrm{p}=0.092$, with interventions with fewer sessions tending to be more likely to conjointly decrease eating disorder and depressive symptoms.

\section{Discussion}

The aim of the present study was to review the efficacy of indicated prevention and early interventions programs in decreasing concurrent depressive and eating disorder symptoms. Overall, the findings revealed that while the majority of interventions were successful in achieving decreases in eating disorder symptoms, fewer than half of the interventions identified were successful in decreasing both eating disorder and depressive symptoms. These results suggest that existing interventions may be limited in their overall impact and their long-term effects as remaining depressive symptoms could increase the likelihood of later recrudescence in eating disorder symptomatology [1]. Furthermore, these findings highlight the need for increased attention to comorbid depressive symptoms in intervention development and evaluation.

The findings from our review reveal that while $92 \%$ of the interventions resulted in significant decreases in eating disorder symptoms, only $42 \%$ were successfully in decreasing concurrent depressive and eating disorder symptoms. An important consideration lies in the fact that all of the interventions identified were primarily designed to target eating disorder symptoms, thus publication bias might have affected these ratios and made it more unlikely for our review to identify interventions successful only in decreasing depressive symptoms. Nevertheless, despite the seemingly widespread recognition of the important role of depressive symptoms in eating disorder pathology, illustrated by the frequent inclusion of depressive symptoms as a secondary outcome and the consideration of the effects of eating disorder interventions on depressive symptoms or negative affect in meta-analyses of eating disorder prevention interventions [19], our findings suggest that eating disorder interventions reveal a limited capacity to decrease depressive symptoms. Interestingly, while their importance as a secondary outcome is recognized, the failure to impact depressive symptoms seems to have received little attention. One potential explanation could be a lack of clarity in the conceptualization of depressive symptoms within intervention evaluation. Depressive symptomatology might be assessed as a control factor that could moderate intervention effects, and consequently the lack of intervention effects on this dimension would not be interpreted as a limitation of the intervention success. However, the studies included in the present review assessed for change in depressive symptoms, and frequently referred to it as a secondary outcome, suggesting that the intervention had been hypothesized to positively impact depressive symptoms.

The limited success of the interventions included in this review in decreasing depressive symptoms given their general success in decreasing eating disorder symptoms, suggests that, consistent with theories of comorbidity in a subset of individuals at least, depressive symptoms may not be secondary to eating disorder symptomatology [10]. Some 
Table 1 Characteristics of studies included in the systematic review

\begin{tabular}{|c|c|c|c|c|c|c|c|c|c|c|c|}
\hline Study & $\begin{array}{l}\text { N intervention; } \\
\text { N control; } \\
\text { Gender }\end{array}$ & $\begin{array}{l}\text { Mean } \\
\text { age }\end{array}$ & Country & $\begin{array}{l}\text { Inclusion } \\
\text { criteria }\end{array}$ & $\begin{array}{l}\text { Intervention; } \\
\text { number of } \\
\text { sessions }\end{array}$ & $\begin{array}{l}\text { Depression } \\
\text { assessment } \\
\text { instrument }\end{array}$ & $p$-post & $\begin{array}{l}p-\text { follow } \\
\text { up }\end{array}$ & $\begin{array}{l}\text { Eating } \\
\text { disorder } \\
\text { symptoms }\end{array}$ & $p$-post & $\begin{array}{l}p-\text { follow } \\
\text { up }\end{array}$ \\
\hline \multirow[t]{3}{*}{ Alloway [33] } & \multirow{3}{*}{$\begin{array}{l}N \text { intervention }=8 ; \\
N \text { control }=6 ; F\end{array}$} & \multirow[t]{3}{*}{32} & \multirow[t]{3}{*}{ Canada } & Diabetes & \multirow{3}{*}{$\begin{array}{l}\text { Psycho-education; } \\
6 \text { sessions }\end{array}$} & \multirow{3}{*}{$\begin{array}{l}\text { Beck depression } \\
\text { inventory }\end{array}$} & \multirow[t]{3}{*}{ ns } & \multirow[t]{3}{*}{ ns } & & \multirow[t]{3}{*}{ ns } & \multirow[t]{3}{*}{ ns } \\
\hline & & & & $\mathrm{EDI} \geq 40$ & & & & & EDI & & \\
\hline & & & & EAT $\geq 17$ & & & & & EDI & & \\
\hline \multirow[t]{2}{*}{ Banasiak [34] } & \multirow{2}{*}{$\begin{array}{l}N \text { intervention }=54 ; \\
N \text { control }=55 ; \mathrm{F}\end{array}$} & \multirow[t]{2}{*}{45} & \multirow[t]{2}{*}{ Australia } & \multirow{2}{*}{$\begin{array}{l}\text { meeting full or modified } \\
\text { criteria for BN }\end{array}$} & \multirow{2}{*}{$\begin{array}{l}\text { Guided self-help vs } \\
\text { TAU; } 8 \text { sessions }\end{array}$} & \multirow{2}{*}{$\begin{array}{l}\text { Beck depression } \\
\text { inventory }\end{array}$} & \multirow[t]{2}{*}{ * } & \multirow[t]{2}{*}{ N/A } & EDE-Q & * & N/A \\
\hline & & & & & & & & & EDI & * & N/A \\
\hline \multirow[t]{3}{*}{ Bearman [35] } & \multirow{3}{*}{$\begin{array}{l}N \text { intervention }=38 ; \\
N \text { control }=35 ; \mathrm{F}\end{array}$} & \multirow[t]{3}{*}{18.9} & \multirow[t]{3}{*}{ USA } & \multirow[t]{3}{*}{ Self-selected undergrads } & \multirow{3}{*}{$\begin{array}{l}\text { CBT vs control; } \\
4 \text { sessions }\end{array}$} & \multirow{3}{*}{$\begin{array}{l}\text { Beck depression } \\
\text { inventory }\end{array}$} & \multirow[t]{3}{*}{ * } & \multirow[t]{3}{*}{ ns } & BPS & * & * \\
\hline & & & & & & & & & DRES & * & * \\
\hline & & & & & & & & & EDE-Q & * & ns \\
\hline Carrard [36] & $\mathrm{N}$ intervention =37; & 36 & Switzerland & 1 OBE a week for the past & Internet CBT vs & Beck depression & ns & N/A & EDE-Q & * & N/A \\
\hline & $\mathrm{N}$ control =37; F & & & 3 months, meeting BED & control; 11 sessions & inventory & & & EDI & * & N/A \\
\hline & & & & & & & & & TFEQ & * & N/A \\
\hline Carrard [37] & $\mathrm{N}$ intervention =22; & 42 & Switzerland & BED patients $30<\mathrm{BMl}<50$ & Internet CBT vs & Beck depression & * & ns & EDE-Q & ns & ns \\
\hline & & & & & control; 11 sessions & inventory & & & TFEQ & ns & ns \\
\hline Carter [38] & $N$ intervention $=28 / 28$ & 27 & USA & $\mathrm{BN}$ & CBT self-help vs & Beck depression & ns & N/A & OBE & * & N/A \\
\hline & N control =29; F & & & & $\begin{array}{l}\text { nonspecific self-help } \\
\text { vs control; } 8 \text { sessions }\end{array}$ & inventory & & & EDE-Q & ns & N/A \\
\hline Fichter [39] & $\mathrm{N}$ intervention =68; & 25 & Germany & AN-B/P patients & Self-help vs waitlist; & Beck depression & ns & N/A & EDI & ns & N/A \\
\hline & & & & & & & & & SIAB-EX & * & N/A \\
\hline Grilo [40] & $N$ intervention =38/37; & 46.5 & USA & BED & CBT vs behavioural & Beck depression & ns & N/A & EDE-Q & * & N/A \\
\hline & N control =15; M \& F & & & & $\begin{array}{l}\text { weight-loss vs control; } \\
12 \text { sessions }\end{array}$ & inventory & & & TFEQ & * & N/A \\
\hline Grilo [41] & $\begin{array}{l}N \text { intervention }=24 ; \\
N \text { control }=24 ; M \& F\end{array}$ & 45.8 & USA & Obese with BED & $\begin{array}{l}\text { Self-help CBT vs TAU; } \\
8 \text { sessions }\end{array}$ & $\begin{array}{l}\text { Beck depression } \\
\text { inventory }\end{array}$ & ns & N/A & EDE-Q & * & N/A \\
\hline Heinicke [42] & $\mathrm{N}$ intervention $=36$ & 14.4 & Australia & Self-selected for body image & CBT vs WT; & Beck depression & * & * & BSQ & * & * \\
\hline & N control =37; F & & & or eating concerns & 6 sessions & inventory & & & DEBQ & * & * \\
\hline & & & & & & & & & EWLB & * & * \\
\hline & & & & & & & & & EDI & * & * \\
\hline & & & & & & & & & SATAQ & * & * \\
\hline Jacobi [43] & $\mathrm{N}$ intervention $=51$ & 22.3 & Germany & $>42$ WCS & Internet CBT vs & Beck depression & $\mathrm{d}=.14$ & $\mathrm{~d}=.15$ & EDE-Q & $d=.23-.35$ & $d=.41-.62$ \\
\hline & & & & & $\begin{array}{l}\text { control; } \\
8 \text { sessions }\end{array}$ & inventory & & & EDI & $d=.08-32$ & $d=.35-.54$ \\
\hline Ljotsson [44] & $\mathrm{N}$ intervention =35; & 34 & Sweden & MADRS score $<30$ BED or BN & Self-help CBT vs & Montgome-ry & * & * & EDE-Q & * & * \\
\hline & N control =36; M \& F & & & full or sub-threshold & control; 12 sessions & $\begin{array}{l}\text { asberg } \\
\text { depression }\end{array}$ & & & EDI & * & * \\
\hline & & & & & & rating scale & & & BSQ & * & * \\
\hline
\end{tabular}


Table 1 Characteristics of studies included in the systematic review (Continued)

\begin{tabular}{|c|c|c|c|c|c|c|c|c|c|c|c|}
\hline \multirow[t]{5}{*}{ McLean [45] } & \multirow{5}{*}{$\begin{array}{l}\mathrm{N} \text { intervention }=32 ; \mathrm{N} \\
\text { control }=3629 \mathrm{~F}\end{array}$} & \multirow[t]{5}{*}{43.92} & \multirow[t]{5}{*}{ Australia } & \multirow{5}{*}{$\begin{array}{l}\mathrm{BSQ} \geq 90 \text { or EDE-Q } \\
\mathrm{WSC} \geq 3.5\end{array}$} & \multirow{5}{*}{$\begin{array}{l}\text { CBT vs control; } \\
8 \text { sessions }\end{array}$} & \multirow[t]{5}{*}{ KDS } & \multirow[t]{5}{*}{ ns } & \multirow[t]{5}{*}{$*$} & BSQ & $*$ & * \\
\hline & & & & & & & & & EDEQ & * & * \\
\hline & & & & & & & & & BIAQ & * & * \\
\hline & & & & & & & & & SATAQ & * & * \\
\hline & & & & & & & & & DEBQ & * & * \\
\hline \multirow[t]{6}{*}{ Mitchell [46] } & \multirow{6}{*}{$\begin{array}{l}\mathrm{N} \text { intervention =30/33; } \\
\mathrm{N} \text { control =30; F }\end{array}$} & & \multirow[t]{6}{*}{ USA } & \multirow[t]{6}{*}{ Self-selected } & \multirow{6}{*}{$\begin{array}{l}\text { CD vs yoga vs control; } \\
6 \text { sessions }\end{array}$} & \multirow{6}{*}{ CES-D } & \multirow[t]{6}{*}{ ns } & \multirow[t]{6}{*}{ N/A } & EDDS & $*(C D)$ & N/A \\
\hline & & & & & & & & & BES & ns & N/A \\
\hline & & & & & & & & & EDI & $*(C D)$ & N/A \\
\hline & & & & & & & & & IBSS & ns & N/A \\
\hline & & & & & & & & & TFEQ & ns & N/A \\
\hline & & & & & & & & & BSQ & ns & N/A \\
\hline \multirow[t]{4}{*}{ O'Brien [47] } & \multirow{4}{*}{$\begin{array}{l}\mathrm{N} \text { intervention }=13 ; \mathrm{N} \\
\text { control }=11 ; \mathrm{F}\end{array}$} & \multirow[t]{4}{*}{22.2} & \multirow[t]{4}{*}{ Canada } & \multirow{4}{*}{$\begin{array}{l}\text { EDI > 10, skipping } 2 \\
\text { meals a week }\end{array}$} & \multirow{4}{*}{$\begin{array}{l}\text { Control vs psycho- } \\
\text { education; } 8 \text { sessions }\end{array}$} & \multirow{4}{*}{$\begin{array}{l}\text { Beck depression } \\
\text { inventory }\end{array}$} & \multirow[t]{4}{*}{ ns } & \multirow[t]{4}{*}{ ns } & BULIT & $*$ & * \\
\hline & & & & & & & & & BSQ & * & ns \\
\hline & & & & & & & & & EAT & * & * \\
\hline & & & & & & & & & FFS & * & ns \\
\hline \multirow[t]{5}{*}{ Paxton [48] } & $N$ intervention $=42 / 37$; & 25 & Australia & $\mathrm{BSQ}>100$, or $\mathrm{BSQ}=90-99$ & CBT vs internet CBT vs & Beck depression & * & N/A & BSQ & * & N/A \\
\hline & & & & AND BULIT-R > 104 & waitlist; 8 sessions & inventory & & & BULIT & * & N/A \\
\hline & & & & & & & & & DEBQ & * & N/A \\
\hline & & & & & & & & & BIAQ & * & N/A \\
\hline & & & & & & & & & SATAQ & * & N/A \\
\hline Robinson [49] & $N$ intervention $=36 / 34$ & 28 & UK & $\mathrm{BN}, \mathrm{BED}$ or EDNOS & eCBT vs writing vs & Beck depression & ns & N/A & QEDD & * & N/A \\
\hline & N control = L/; M \& & & & & $\begin{array}{l}\text { waltlist; } \\
24 \text { sessions }\end{array}$ & Inventory & & & BITE & ns & N/A \\
\hline Sánchez [50] & $\begin{array}{l}\mathrm{N} \text { intervention =38; } \mathrm{N} \\
\text { control =38; } \mathrm{F}\end{array}$ & 23.9 & UK & BN or EDNOS & $\begin{array}{l}\text { iCBT vs waitlist; } 8 \\
\text { sessions }\end{array}$ & $\begin{array}{l}\text { Hospital anxiety } \\
\text { and depression } \\
\text { scale }\end{array}$ & N/A & $*$ & EDE-Q & N/A & * \\
\hline Stice [51] & $N$ intervention $=203$ & 21.6 & USA & Self-selected and & CD vs education & Beck depression & * & $*$ & EDDI & * & * \\
\hline & N control = $205 ;$ t & & & phone screened & brochure; 4 sessions & Inventory & & & DRES & * & * \\
\hline & & & & & & & & & BPS & * & * \\
\hline Stice [52] & $\mathrm{N}$ intervention $=25 ; \mathrm{N}$ & 21.3 & USA & Self-selected into eating & Psycho-education vs & Beck depression & ns & ns & IBSS & * & * \\
\hline & control =70; F & & & disorders seminar & control; 28 sessions & inventory & & & BPS & * & * \\
\hline & & & & & & & & & DRES & * & * \\
\hline & & & & & & & & & EDDS & * & * \\
\hline Stice [53] & N intervention $=139$; & 15.7 & USA & Self-selected & CD vs control; & CES-D & ns & ns & IBSS & * & ns \\
\hline & N control = $16 / ;$ & & & & 4 sessions & & & & BPS & * & * \\
\hline
\end{tabular}


Table 1 Characteristics of studies included in the systematic review (Continued)

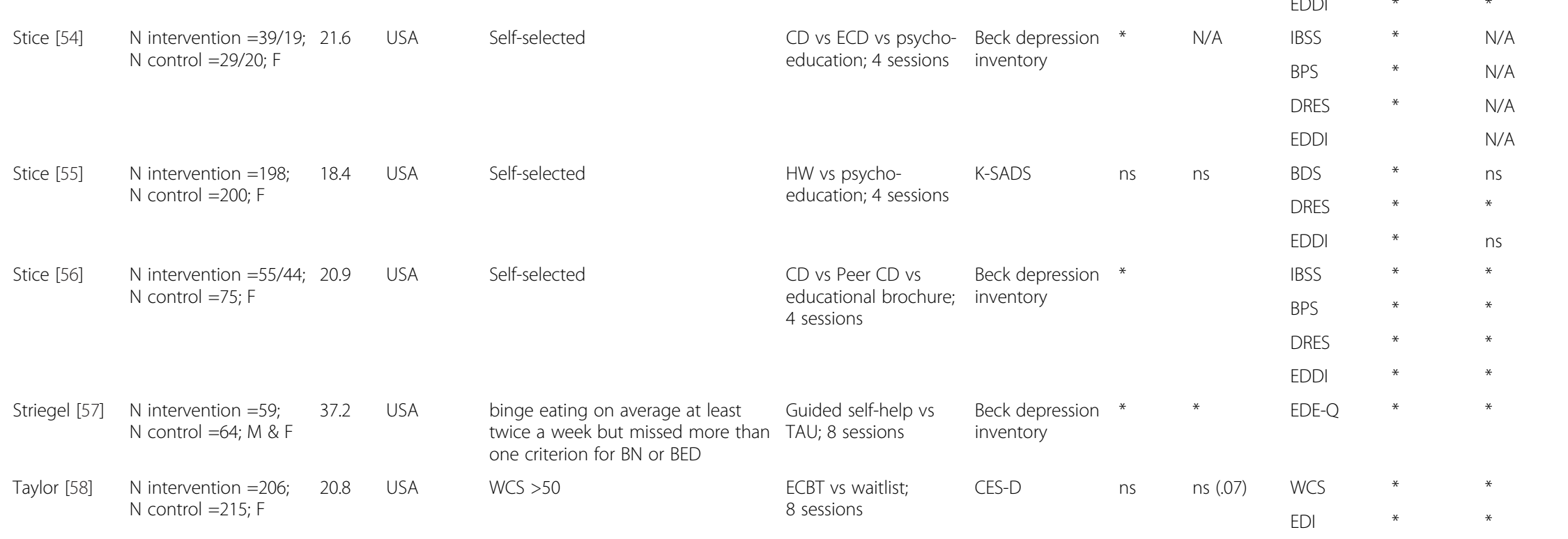

Note: BED = Binge Eating Disorder; BES = Binge Eating Scale [59]; BIAQ = Body Image Avoidance Questionnaire [60]; BITE = Bulimia Investigatory Test Edinburgh [61]; BN = Bulimia nervosa; BPS = Satisfaction and Dissatisfaction with Body Parts Scale [62]; BPSS = BSQ = Body Shape Questionnaire [63]; BULIT = Bulimia Test Revised [64]; Beck Depression Inventory [28]; CBT = Cognitive Behavioural Therapy; CES-D = The Center for Epidemiologic Studies Depression Scale [29]; DRES = Dutch Restrained Eating Scale [65]; EAT = Eating Attitudes Test [66]; EDDI = Eating Disorder Diagnostic Interview [53]; EDDS = Eating Disorder Diagnostic Scale [67]; $\mathrm{EDE}-\mathrm{Q}=$ Eating Disorder Examination Questionnaire [68]; EDI = Eating Disorders Inventory [69]; EDNOS = Eating Disorder Not otherwise Specified; EWLB = Extreme Weight Loss Behaviors; IBSS = Ideal Body Stereotype Scale [70]; FFS = Forbidden Food Survey [71]; Hospital Anxiety and Depression Scale [32]; KDS = Kessler Distress Scale [31]; K-SADS Schedule for Affective Disorders and Schizophrenia for School-Age Children [30]; MADRS = Montgomery Asberg Depression Rating Scale [72]; OBE = Objective Binge Episodes; SATAQ = Sociocultural Attitudes Towards Appearance Questionnaire [73]; SIAB-EX = Structured Inventory for Anorexic and Bulimic Disorders [74]; TAU = treatment as usual; TFEQ = Three Factor Eating Questionnaire [75]; WCS = Weight and Shape Concerns Scale [76].

${ }^{*} p<.05$ or lower, ns $=$ non-significant, that is $p>.05$. 
Table 2 Characteristics of studies according to their success in decreasing depressive symptoms

\begin{tabular}{|c|c|c|c|c|c|}
\hline & \multirow{3}{*}{ Range } & \multicolumn{2}{|c|}{ Decreases in depressive symptoms ${ }^{a}$} & \multicolumn{2}{|c|}{$\begin{array}{l}\text { Decreases in both depressive and } \\
\text { eating disorder symptoms }\end{array}$} \\
\hline & & $\begin{array}{l}\text { Significant } \\
\text { decrease }\end{array}$ & $\begin{array}{l}\text { No significant } \\
\text { decrease }\end{array}$ & $\begin{array}{l}\text { Significant } \\
\text { decrease }\end{array}$ & $\begin{array}{l}\text { No significant } \\
\text { decrease }\end{array}$ \\
\hline & & (12 studies) & (15 studies) & (11 studies) & (16 studies) \\
\hline Participant age [mean years, (SD)] & $\begin{array}{l}14.4- \\
46.5\end{array}$ & $27.2(9.8)$ & $28.7(10.5)$ & $25.4(8.8)$ & $33.3(10.7)$ \\
\hline Number of sessions[mean (SD)] & $4-28$ & $7.1(2.7)$ & $10.1(7.1)$ & $6.7(2.4)$ & $10.4(7.1)$ \\
\hline 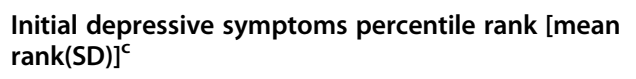 & $55-99$ & $88.1(6.9)$ & $85.4(13.4)$ & $87.1(7.8)$ & $86.3(13.1)$ \\
\hline Use of a screening cut-off score, $\mathrm{N}(\%)$ & & $7(58 \%)$ & $10(67 \%)$ & $6(55 \%)$ & $11(69 \%)$ \\
\hline Face to face format, $\mathrm{N}(\%)$ & & $8(67 \%)$ & $10(67 \%)$ & $9(82 \%)$ & $9(56 \%)$ \\
\hline CBT theoretical framework, $\mathrm{N}(\%)$ & & $9(75 \%)$ & $8(53 \%)$ & $8(73 \%)$ & $9(56 \%)$ \\
\hline $\begin{array}{l}\text { Content targeting negative emotions and } \\
\text { cognitions, } \mathrm{N}(\%)\end{array}$ & & $9(75 \%)$ & $10(37 \%)$ & $9(82 \%)$ & $10(62 \%)$ \\
\hline
\end{tabular}

${ }^{a}$ For the 12 studies that found significant decreases in depressive symptoms, and the 15 that found no significant decrease, the mean age of participants, the mean depressive symptoms percentile rank at baseline, and the number of studies using a cut-off score, face-to face format, CBT framework, and content targeting emotions and cognitions are presented.

${ }^{\mathrm{b}}$ The same information as in column ${ }^{\mathrm{a}}$ is provided for the 11 studies that found significant decreases in both depressive and eating disorder symptoms, and the 16 that did not.

'Higher rank indicates that the participants in the study reported higher initial levels of depression.

authors have suggested that individuals suffering from eating disorder symptoms may experience depressive symptoms due to the burden of the illness [5]. However, the finding that the improvement of eating disorder symptomatology was not robustly associated with improvement in depressive symptoms, suggests this may not be the only mechanism accounting for the comorbidity and supports theories highlighting common etiological factors [10].

Overall, our proposed moderating factors were not predictive of success in decreasing depressive symptoms. One potential explanation for this failure is that we lacked statistical power due to using dichotomous variables as outcomes and for many moderators, or that the continuous variables assessed lacked variability. However, it might also be that variables other than those assessed in these studies, predict intervention effects on depressive symptoms. Our finding did reveal a trend-level finding regarding number of sessions, with shorter interventions revealing a higher likelihood of decreasing both eating disorder and depressive symptoms. This finding is consistent with those of metaanalytic reviews of interventions targeting depressive symptoms among children and adolescents [77]. These authors hypothesized that engagement may be higher with shorter programs, accounting for the stronger effects.

Our study was limited by some aspects of the available data. We used participant recruitment criteria (self-selected versus screened) as a proxy for eating disorder severity in part due to the wide variability in eating disorder instruments used and the lack of available normative data for some of those instruments. Using a more sensitive measure of eating disorder severity might have produced different results. Furthermore, while some studies provided rates of diagnosable depression in their sample of baseline, rates of depression at post-test were not available, precluding examination of decreases in diagnosable depression.

Nevertheless, these findings reveal the gap in knowledge and practice regarding the treatment of concurrent eating disorder and depressive symptoms and suggest some directions for future work:

(1) Increasing our understanding of the course of depressive symptoms in relation to eating disorder symptoms during interventions might help clarify the mechanism of change in depressive symptoms and identify individuals benefiting less from the intervention effects on depressive symptoms.

(2) Exploring participants' experience of the causes of depressive symptoms, in particular as related or unrelated to their eating disorder symptoms, would contribute to increasing our understanding of the partial success of eating disorder interventions in decreasing concurrent eating disorder and depressive symptoms.

(3) The development and evaluation of depression-specific modules in eating disorder interventions would provide evidence of increased efficacy in decreasing depressive symptoms.

(4) Including measures of eating disorder symptoms in interventions primarily targeting depressive symptoms could further inform interventions for these comorbid concerns, and contribute to greater treatment efficiency. 


\section{Conclusions}

Eating disorder and depressive symptoms are frequently comorbid and, in recognition of this, eating disorder interventions have often assessed depressive symptoms. The effect indicated prevention and early intervention programs on depressive symptoms is somewhat limited, however, and the characteristics of successful interventions are unclear. Further efforts are required to develop interventions that are successful in decreasing both eating disorder and depressive symptoms in order to increase treatment efficiency and the maintenance of therapeutic effects.

\section{Competing interests}

The authors declare that they have no competing interests.

\section{Authors' contributions}

RR conducted the literature search, data extraction and analysis, and prepared the manuscript. SP reviewed data extraction and interpretation, and contributed to writing of manuscript. Both authors read and approved the final manuscript.

\section{Authors' information}

Rachel F Rodgers this work was conducted as a Honorary Visiting Academic at La Trobe University.

\section{Acknowledgements}

The publication costs of this paper were supported by beyondblue. The authors are responsible for all content.

\section{Author details}

${ }^{1}$ Department of Counseling and Applied Educational Psychology, Northeastern University, Boston, USA. 'Laboratoire de Stress Traumatique, Universite Paul Sabatier, Toulouse, France. ${ }^{3}$ La Trobe University, Melbourne, Australia.

Received: 22 September 2014 Accepted: 12 October 2014 Published online: 13 November 2014

\section{References}

1. Berkman ND, Lohr KN, Bulik CM: Outcomes of eating disorders: a systematic review of the literature. Int J Eat Disord 2007, 40:293-309.

2. Hudson Jl, Hiripi E, Pope HG Jr, Kessler RC: The prevalence and correlates of eating disorders in the National Comorbidity Survey Replication. Biol Psychiatry 2007, 61:348-358.

3. Masheb RM, Grilo CM: Examination of predictors and moderators for self-help treatments of binge-eating disorder. J Consult Clin Psychol 2008 76(5):900-904.

4. Von Brachel R, Hل/atzel K, Hirschfeld G, Rieger E, Schmidt U, Kosfelder J Hechler T, Schulte D, Vocks S: Internet-based motivation program for women with eating disorders: eating disorder pathology and depressive mood predict dropout. J Med Internet Res 2014, 16:e92.

5. Stice E, Hayward C, Cameron RP, Killen JD, Taylor CB: Body-image and eating disturbances predict onset of depression among female adolescents: a longitudinal study. J Abnorm Psychol 2000, 109:438-444.

6. Stice E, Presnell K, Spangler D: Risk factors for binge eating onset in adolescent girls: a 2-year prospective investigation. Health Psychol 2002, 21:131-138.

7. Presnell K, Stice E, Seidel A, Madeley MC: Depression and eating pathology: prospective reciprocal relations in adolescents. Clin Psychol Psychother 2009, 16:357-365.

8. Wade TD, Bulik CM, Neale M, Kendler KS: Anorexia nervosa and major depression: shared genetic and environmental risk factors. Am J Psychiatry 2000, 157:469-471.

9. Mangweth B, Hudson J, Pope H, Hausmann A, De Col C, Laird N, Beibl W, Tsuang M: Family study of the aggregation of eating disorders and mood disorders. Psychol Med 2003, 33:1319-1323.
10. Bulik CM: Anxiety, Depression, and Eating Disorders. In Eating Disorders and Obesity: A Comprehensive Handbook. 2nd edition. Edited by Fairburn CG, Brownell KD. ; 2002:193-198.

11. Kaye W: Neurobiology of anorexia and bulimia nervosa. Physiol Behav 2008, 94:121-135.

12. Cooper MJ: Cognitive theory in anorexia nervosa and bulimia nervosa: progress, development and future directions. Clin Psychol Rev 2005, 25:511-531.

13. Benas JS, Gibb BE: Weight-related teasing, dysfunctional cognitions, and symptoms of depression and eating disturbances. Cogn Ther Res 2008, 32(2):143-160

14. Cooper MJ: Beliefs and their relationship to eating attitudes and depressive symptoms in men. Eat Behav 2006, 7:423-426.

15. Aldao A, Nolen-Hoeksema S, Schweizer S: Emotion-regulation strategies across psychopathology: a meta-analytic review. Clin Psychol Rev 2010, 30:217-237

16. Fredrickson BL, Roberts TÄ: Objectification theory. Psychol Women Q 1997 21:173-206

17. Tiggemann M, Kuring JK: The role of body objectification in disordered eating and depressed mood. Br J Clin Psychol 2004, 43:299-311.

18. Gilbert S, Thompson JK: Feminist explanations of the development of eating disorders: common themes, research findings, and methodological issues. Clin Psychol Sci Pract 1996, 3:183-202.

19. Stice $E$, Shaw $H$, Marti CN: A meta-analytic review of eating disorder prevention programs: encouraging findings. Ann Rev Clin Psychol 2007 3:207-231.

20. Stice $E$, Rohde $P$, Shaw H, Gau J: An effectiveness trial of a selected dissonance-based eating disorder prevention program for female high school students: long-term effects. J Consult Clin Psychol 2011, 79:500-508.

21. Stice $E$, Ragan J: A preliminary controlled evaluation of an eating disturbance psychoeducational intervention for college students. Int J Eat Disord 2002, 31:159-171.

22. Whitty P, Gilbody S: NICE, but will they help people with depression? The new national institute for clinical excellence depression guidelines. Br J Psychiatry 2005, 186:177-178.

23. Moher D, Liberati A, Tetzlaff J, Altman DG: Preferred reporting items for systematic reviews and meta-analyses: the PRISMA statement. PLoS Med 2009, 6:e1000097.

24. Medicine NRCalo: Preventing Mental, Emotional, and Behavioral Disorders Among Young People: Progress and Possibilities. Washington DC: The National Academic Press; 2009.

25. Wilson GT, Vitousek KM, Loeb KL: Stepped care treatment for eating disorders. J Consult Clin Psychol 2000, 68:564-572.

26. Crawford J, Cayley C, Lovibond PF, Wilson PH, Hartley C: Percentile norms and accompanying interval estimates from an Australian general adult population sample for self-report mood scales (BAI, BDI, CRSD, CES-D, DASS, DASS-21, STAI-X, STAI-Y, SRDS, and SRAS). Aust Psychol 2011, 46:3-14

27. Slade T, Grove R, Burgess P: Kessler psychological distress scale: normative data from the 2007 Australian national survey of mental health and wellbeing. Aust N Z J Psychiatry 2011, 45:308-316.

28. Beck AT, Ward C, Mendelson M: Beck depression inventory (BDI) Arch Gen Psychiatry 1961, 4:561-571.

29. Radloff LS: The CES-D scale a self-report depression scale for research in the general population. Appl Psychol Meas 1977, 1:385-401.

30. Kaufman J, Birmaher B, Brent D, Rao U, Flynn C, Moreci P, Williamson D, Ryan N: Schedule for affective disorders and schizophrenia for school-age children-present and lifetime version (K-SADS-PL): initial reliability and validity data. J Am Acad Child Adolesc Psychiatry 1997, 36:980-988.

31. Kessler RC, Andrews G, Colpe LJ, Hiripi E, Mroczek DK, Normand S-LT, Walters EE, Zaslavsky AM: Short screening scales to monitor population prevalences and trends in non-specific psychological distress. Psychol Med 2002, 32:959-976.

32. Zigmond AS, Snaith RP: The hospital anxiety and depression scale. Acta Psychiatr Scand 1983, 67:361-370.

33. Alloway SC, Toth EL, McCargar $\sqcup$ : Effectiveness of a group psychoeducation program for the treatment of subclinical disordered eating in women with type 1 diabetes. Can J Diet Pract Res 2000, 62:188-192.

34. Banasiak SJ, Paxton SJ, Hay P: Guided self-help for bulimia nervosa in primary care: a randomized controlled trial. Psychol Med 2005, 35:1283-1294. 
35. Bearman SK, Stice E, Chase A: Evaluation of an intervention targeting both depressive and bulimic pathology: a randomized prevention trial. Behav Ther 2003, 34:277-293.

36. Carrard I, Crépin C, Rouget P, Lam T, Golay A, Van der Linden M: Randomised controlled trial of a guided self-help treatment on the internet for binge eating disorder. Behav Res Ther 2011, 49:482-491.

37. Carrard I, Crépin C, Rouget P, Lam T, van der Linden M, Alain Golay A: Acceptance and efficacy of a guided Internet self-help treatment program for obese patients with binge eating disorder. Clin Pract Epidemiol Ment Health 2011, 7:8-18.

38. Carter JC, Olmsted MP, Kaplan AS, McCabe RE, Mills JS, Aimé A: Self-help for bulimia nervosa: a randomized controlled trial. Am J Psychiatry 2003, 160:973-978.

39. Fichter M, Cebulla M, Quadflieg N, Naab S: Guided self-help for binge eating/purging anorexia nervosa before inpatient treatment. Psychother Res 2008, 18:594-603.

40. Grilo CM, Masheb RM: A randomized controlled comparison of guided self-help cognitive behavioral therapy and behavioral weight loss for binge eating disorder. Behav Res Ther 2005, 43:1509-1525.

41. Grilo CM, White MA, Gueorguieva R, Barnes RD, Masheb RM: Self-help for binge eating disorder in primary care: a randomized controlled trial with ethnically and racially diverse obese patients. Behav Res Ther 2013, 51:855-861.

42. Heinicke BE, Paxton SJ, McLean SA, Wertheim EH: Internet-delivered targeted group intervention for body dissatisfaction and disordered eating in adolescent girls: a randomized controlled trial. J Abnorm Child Psychol 2007, 35:379-391.

43. Jacobi C, Völker U, Trockel MT, Taylor CB: Effects of an internet-based intervention for subthreshold eating disorders: a randomized controlled trial. Behav Res Ther 2012, 50:93-99.

44. Ljotsson B, Lundin C, Mitsell K, Carlbring P, Ramklint M, Ghaderi A: Remote treatment of bulimia nervosa and binge eating disorder: a randomized trial of Internet-assisted cognitive behavioural therapy. Behav Res Ther 2007, 45:649-661.

45. McLean SA, Paxton SJ, Wertheim EH: A body image and disordered eating intervention for women in midlife: a randomized controlled trial. J Consult Clin Psychol 2011, 79:751-758.

46. Mitchell KS, Mazzeo SE, Rausch SM, Cooke KL: Innovative interventions for disordered eating: evaluating dissonance-based and yoga interventions. Int J Eat Disord 2007, 40:120-128.

47. O'Brien KM, LeBow MD: Reducing maladaptive weight management practices: developing a psychoeducational intervention program. Eat Behav 2007, 8:195-210.

48. Paxton SJ, McLean SA, Gollings EK, Faulkner C, Wertheim EH: Comparison of face-to-face and internet interventions for body image and eating problems in adult women: an RCT. Int J Eat Disord 2007, 40:692-704.

49. Robinson P, Serfaty M: Getting better byte by byte: a pilot randomised controlled trial of email therapy for bulimia nervosa and binge eating disorder. Eur Eat Disord Rev 2008, 16:84-93.

50. Sánchez-Ortiz V, Munro C, Stahl D, House J, Startup H, Treasure J, Williams C, Schmidt U: A randomized controlled trial of internet-based cognitive-behavioural therapy for bulimia nervosa or related disorders in a student population. Psychol Med 2011, 41:407-417

51. Stice $E$, Butryn ML, Rohde $P$, Shaw $H$, Marti CN: An effectiveness trial of a new enhanced dissonance eating disorder prevention program among female college students. Behav Res Ther 2013, 51:862-871.

52. Stice E, Orjada K, Tristan J: Trial of a psychoeducational eating disturbance intervention for college women: a replication and extension. Int J Eat Disord 2006, 39:233-239.

53. Stice E, Rohde P, Gau J, Shaw H: An effectiveness trial of a dissonancebased eating disorder prevention program for high-risk adolescents girls. J Consult Clin Psychol 2009, 77:825-834.

54. Stice $E$, Rohde $\mathrm{P}$, Durant $\mathrm{S}$, Shaw $\mathrm{H}$ : A preliminary trial of a prototype internet dissonance-based eating disorder prevention program for young women with body image concerns. J Consult Clin Psychol 2012, 80:907-916.

55. Stice $E$, Rohde $P$, Shaw $H$, Marti CN: Efficacy trial of a selective prevention program targeting both eating disorder symptoms and unhealthy weight gain among female college students. J Consult Clin Psychol 2012, 80:164-170.
56. Stice E, Rohde P, Durant S, Shaw H, Wade E: Effectiveness of peer-led dissonance-based eating disorder prevention groups: results from two randomized pilot trials. Behav Res Ther 2013, 51:197-206.

57. Striegel-Moore RH, Wilson GT, DeBar L, Perrin N, Lynch F, Rosselli F, Kraemer $\mathrm{HC}$ : Cognitive behavioral guided self-help for the treatment of recurrent binge eating. J Consult Clin Psychol 2010, 78:312-321.

58. Taylor CB, Bryson S, Luce KH, Cunning D, Doyle AC, Abascal LB, Rockwell R, Dev $P$, Winzelberg AJ, Wilfley DE: Prevention of eating disorders in at-risk college-age women. Arch Gen Psychiatry 2006, 63:881-888.

59. Gormally J, Black S, Daston S, Rardin D: The assessment of binge eating severity among obese persons. Addict Behav 1982, 7:47-55.

60. Rosen JC, Srebnik D, Saltzberg E, Wendt S: Development of a body image avoidance questionnaire. Psychol Assess J Consult Clin Psychol 1991, 3:32-37.

61. Henderson M, Freeman CP: A self-rating scale for bulimia. The'BITE'. Br J Psychiatry 1987, 150:18-24.

62. Berscheid E, Walster E, Bohrnstedt G: The happy American body: a survey report. Psychol Today 1973, 7:119-131.

63. Cooper PJ, Taylor MJ, Cooper Z, Fairbum CG: The development and validation of the body shape questionnaire. Int J Eat Disord 1987, 6:485-494.

64. Thelen MH, Farmer J, Wonderlich S, Smith M: A revision of the bulimia test: the BULIT-R. Psychol Assess J Consult Clin Psychol 1991, 3:119-124.

65. Van Strien T, Frijters JE, Van Staveren WA, Defares PB, Deurenberg P: The predictive validity of the Dutch restrained eating scale. Int J Eat Disord 1986, 5:747-755.

66. Garner DM, Garfinkel PE: The eating attitudes test: an index of the symptoms of anorexia nervosa. Psychol Med 1979, 9:273-279.

67. Stice E, Telch CF, Rizvi SL: Development and validation of the eating disorder diagnostic scale: a brief self-report measure of anorexia, bulimia, and binge-eating disorder. Psychol Assess 2000, 12:123-131.

68. Fairburn CG, Beglin SJ: Assessment of eating disorders: interview or self-report questionnaire? Int J Eat Disord 1994, 16:363-370.

69. Garner DM, Olmstead MP, Polivy J: Development and validation of a multidimensional eating disorder inventory for anorexia nervosa and bulimia. Int J Eat Disord 1983, 2:15-34.

70. Stice E, Schupak-Neuberg E, Shaw HE, Stein Rl: Relation of media exposure to eating disorder symptomatology: an examination of mediating mechanisms. J Abnorm Psychol 1994, 103:836-840.

71. Ruggiero L, Williamson D, Davis C, Schlundt DG, Carey MP: Forbidden food survey: measure of bulimic's anticipated emotional reactions to specific foods. Addict Behav 1988, 13:267-274.

72. Svanborg P, Åsberg M: A new self-rating scale for depression and anxiety states based on the comprehensive psychopathological rating scale. Acta Psychiatr Scand 1994, 89:21-28.

73. Thompson JK, van den Berg P, Roehrig M, Guarda AS, Heinberg LJ: The sociocultural attitudes towards appearance scale-3 (SATAQ-3): development and validation. Int J Eat Disord 2004, 35:293-304.

74. Fichter MM, Herpertz S, Quadflieg N, Herpertz-DahImann B: Structured interview for anorexic and bulimic disorders for DSM-IV and ICD-10: updated (third) revision. Int J Eat Disord 1998, 24:227-249.

75. Stunkard AJ, Messick S: The three-factor eating questionnaire to measure dietary restraint, disinhibition and hunger. J Psychosom Res 1985, 29:71-83.

76. Jacobi C, Abascal L, Taylor CB: Screening for eating disorders and high-risk behavior: caution. Int J Eat Disord 2004, 36:280-295.

77. Stice E, Shaw H, Bohon C, Marti CN, Rohde P: A meta-analytic review of depression prevention programs for children and adolescents: factors that predict magnitude of intervention effects. J Consult Clin Psychol 2009, 77:486-503.

\section{doi:10.1186/s40337-014-0030-2}

Cite this article as: Rodgers and Paxton: The impact of indicated prevention and early intervention on co-morbid eating disorder and depressive symptoms: a systematic review. Journal of Eating Disorders 2014 2:30. 